\title{
Evaluating the Combination of Human Chorionic Gonadotropin and Clomiphene Citrate in Treatment of Male Hypogonadotropic Hypogonadism: A Prospective Study
}

\author{
The Son Trinh (D) \\ Nguyen Ba Hung ${ }^{2,3}$ \\ Le Thi Thu Hien ${ }^{2}$ \\ Ngo Anh Tuan (iD) 4 \\ Dinh Cong Pho (D) ${ }^{5}$ \\ Quan Anh Dung (D) 6 \\ Duc Anh Do iD ${ }^{7}$ \\ Ha Duc Quang ${ }^{2}$ \\ Hoang Van $\mathrm{Ai}^{1}$ \\ Pham Ngoc Hung (D) ${ }^{8,9}$ \\ 'Military Institute of Clinical Embryology \\ and Histology, Vietnam Military Medical \\ University, Hanoi, Vietnam; ${ }^{2}$ Andrology \\ and Fertility Hospital of Hanoi - AF \\ Hanoi, Hanoi, Vietnam; ${ }^{3}$ Vinmec Times \\ City International Hospital, Hanoi, \\ Vietnam; ${ }^{4}$ Department of Health \\ Economics, Vietnam Military Medical \\ University, Hanoi, Vietnam; ${ }^{5}$ Department \\ of Infection Control, Military Hospital \\ 103, Vietnam Military Medical University, \\ Hanoi, Vietnam; ${ }^{6}$ Faculty of Medicine, \\ Vietnam Military Medical University, \\ Hanoi, Vietnam; ${ }^{7}$ Faculty of Medicine, \\ University of Medical Sciences of \\ Revolutionary Armed Force (UCIMED de \\ Las FAR), Marianao, Havana, Cuba; \\ ${ }^{8}$ Department of Epidemiology, Vietnam \\ Military Medical University, Hanoi, \\ Vietnam; 'Department of Training, \\ Vietnam Military Medical University, \\ Hanoi, Vietnam
}

Correspondence: Pham Ngoc Hung Vietnam Military Medical University, $\mathrm{Ha}$ Dong District, Hanoi, I00000, Vietnam $\mathrm{Tel}+84939613388$

Email pnhungqy@vmmu.edu.vn
Background: In this study, we evaluated $\mathrm{MHH}$ patients who wished to preserve fertility, assessing the efficacy of a short course (12 months) of a combined hCG +clomiphene citrate. Materials and Methods: The cross-sectional study included 19 patients with hypogonadotropic hypogonadism who were admitted to the Andrology and Fertility Hospital of Hanoi between March 2016 and March 2018. Using hCG every three days in combination with clomiphene citrate $25 \mathrm{mg}$ per day until normal testosterone levels are reached, maintain the dose until spermatozoa are present.

Results: The mean age was $30.2 \pm 5.6$. Differences in penis length between the time before and after treatment were significant $(\mathrm{p}=0.005)$. The average dose of hCG using in our study was $5579 \pm 1773.7$ IU. After treatment 6 months and 12 months, the changes in clinical features in all patients and the total hypogonadotropic hypogonadism group were statistically significant $(p<0.001)$. In particular, the differences in testosterone hormone levels in the partial hypogonadotropic hypogonadism group were also statistically significant $(p=0.03)$. No adverse event was observed in our study. The number of patients appearing sperm in the semen is 9 patients (47.4\%) after 12 months, but most of the sperm were completely deformed $(<1 \%)$, and the average motility in the progressive motility group was below $8 \%$. Conclusion: In conclusion, a combination of hCG and clomiphene citrate may be an option for MHH patients who desired fertility. After 12 months, $47.4 \%$ of patients have sperm in semen but almost all of them were deformity. Hormone profile and secondary sexual characteristics improved significantly. There was no adverse event in our study that considered it as safe therapy.

Keywords: male hypogonadotropic hypogonadism, $\mathrm{MHH}$, total $\mathrm{HH}$, total hypogonadotropic hypogonadism, partital $\mathrm{HH}$, partial hypogonadotropic hypogonadism, clomiphene citrate, $\mathrm{CC}$, human chorionic gonadotropin, hCG, treatment

\section{Introduction}

Male hypogonadism is divided into hypergonadotropic and hypogonadotropic (male hypogonadotropic hypogonadism, $\mathrm{MHH}$ ). $\mathrm{MHH}$ is caused by insufficient secretion of gonadotropins and can be classified into three, namely, congenital, acquired and idiopathic. MHH presents as absent/delayed/arrested sexual maturation and infertility. It has lower prevalence than primary hypogonadism. ${ }^{1}$ To optimise the management of $\mathrm{MHH}$ after confirmation of the disease and consideration of future fertility prospects, the timing and choice of therapeutic intervention are important. Therapy 
involves the use of testosterone to induce the development of secondary sexual characteristics, which in turn leads to puberty and to the maintenance of secondary sexual characteristics. $^{2}$ Therapy is likely to be life-long and requires regular monitoring. Thus, choosing a therapy to optimise responses and avoid adverse events is essential. Testosterone can come from exogenous or endogenous sources. Testosterone replacement therapy using exogenous testosterone is good for improving the quality of life and achieving physical benefits, but this therapy is not suitable for those who are currently seeking fertility., Exogenous testosterone suppresses gonadotropin hormones in the hypothalamus-pituitary-testes axis, which is necessary for normal spermatogenesis to occur. To maintain fertility, exogenous testosterone treatment should be stopped.

Gonadotropin replacement therapy (GRT) induces both spermatogenesis and endogenous testosterone. GRT requires either pulsatile gonadotropin-releasing hormone (GnRH) or gonadotropin administration. Gonadotropins can be self-administered subcutaneously and are not inferior to the more costly GnRH. ${ }^{5}$ Human chorionic gonadotropin (hCG) injection is also an effective therapy for patients with MHH. ${ }^{6}$ The benefits of hCG treatment for MHH patients instead of testosterone was confirmed in the current review. ${ }^{7}$ Clomiphene citrate (CC), a selective oestrogen receptor modulator, is being used (off-label) for testosterone deficiency and does not interfere with spermatogenesis. CC effectively increases serum testosterone with few side effects in men with testosterone deficiency ${ }^{8}$ and is safe for the long-term management of hypogonadism. ${ }^{9}$

We believe in the possible synergy of hCG and CC in MHH patients. In this study, we evaluated the efficacy of a short course (12 months) of the combination $\mathrm{CC}+\mathrm{hCG}$ on MHH patients who wished to preserve their fertility.

\section{Materials and Methods}

This prospective study included 19 azoospermic patients with MHH who were admitted to the Andrology and Fertility Hospital of Hanoi between March 2016 and March 2018.

\section{Patient Selection Criteria}

The MHH diagnosis were made as follows: a male older than or equal to 18 years old without puberty development, with a serum testosterone level $<100 \mathrm{ng} / \mathrm{dL}(3.5 \mathrm{nmol} / \mathrm{L})$ and with a low or normal level of gonadotropins. After
MHH diagnosis, the patients were grouped into two, as follows: partial $\mathrm{MHH}$, onset of puberty but not complete (Tanner 3); and total MHH, childhood reproductive organs remaining and no onset of puberty (Tanner stages 1 and 2). The azoospermia diagnosis was made only after the technician had surveyed a minimum of two semen samples obtained at least 2 weeks apart. The entire semen sediment was centrifuged at a rate of $3000 \mathrm{~g}$ for $15 \mathrm{~min}$ prior to examination, and no spermatozoa were found.

The inclusion criteria were adult MHH patients suffering from azoospermia who seek fertility treatment and who agreed to participate this study. The exclusion criteria included: patients with MHH who are under 18 years old; adult patients with MHH whose tests showed the presence of sperm before the treatment; patients with MHH being treated for acute and sexually transmitted diseases using drugs or chemicals that affect spermatogenesis; patients with MHH who present with other endocrine diseases. Nineteen participants fitted the selection criteria and were enrolled in this study.

\section{Methodology}

This prospective study aimed to evaluate the combination of hCG and CC in the treatment of MHH. The flowchart of study (Figure 1) was shown to clarify the process of this research.

\section{Treatment Plan}

The clinical manifestation, history of medical problems, drug use and family history were recorded at the first visit. The physical examination included age, height, weight, vital signs, Tanner staging (pubic hair), stretch penis length, and testis volume (TV) measured by Prader testicle orchidometer. Laboratory examination included taking peripheral blood tests and measuring gonadotropin level (LH/FSH), total testosterone (TT) level and pituitary/ olfactory nerve MRI scans to diagnose the causes of MHH. This study was approved by the ethics committee of the Andrology and Fertility Hospital of Hanoi.

One of the two brands of hCG (Pregnyl ${ }^{\circledR}$, Merck \& Co., Inc or IVF-C ${ }^{\circledR}$, LG Lifesciences) was used every 3 days, the dose depended on the response of each patient (from $3000 \mathrm{IU}$ to $10,000 \mathrm{IU}$ ) in combination with $\mathrm{CC}$ at $25 \mathrm{mg}$ per day until normal testosterone levels are reached. The dose is maintained until spermatozoa appeared in the semen. Supplementation with HMG or FSH was made if the patient wanted to have children, as shown in the following schema (Figure 1). 


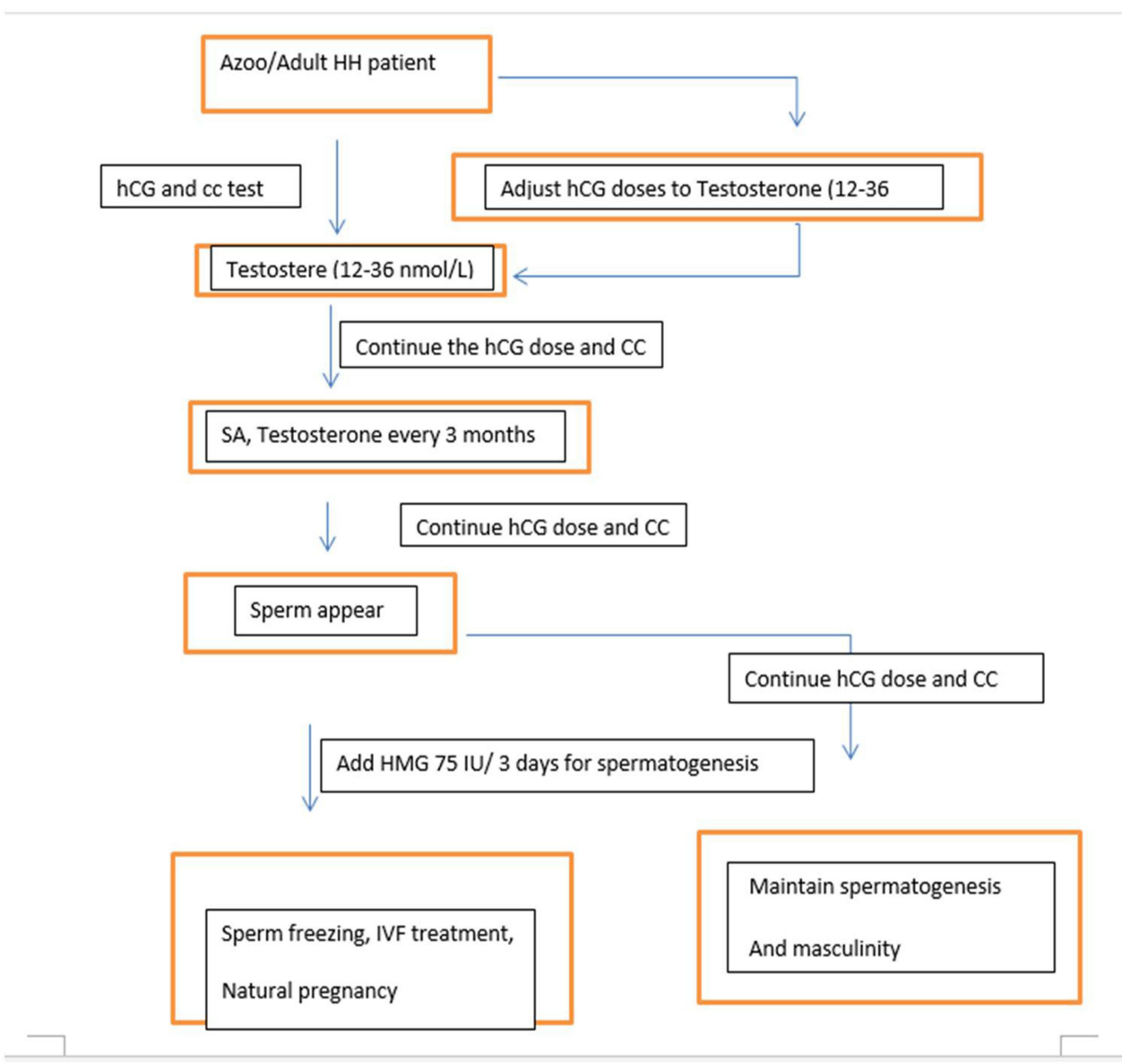

Figure I Flowchart of study.

\section{Outcome and Measurement Outcome}

The primary outcomes were the appearance of spermatozoa in semen after treatment and the total testosterone level. The secondary outcomes were the development of secondary sex characteristics, height, stretch penis length, average bilateral testicular volume, Tanner stage and achievement of childbirth after spermatogenesis (induced treatment).

Patients' follow-up was performed once every 6 months for up to 2 years. Medical checks, TT level measurement and semen analysis were conducted every 3 months. The height, testicular volume, penis length and Tanner stage were measured every 6 months in the first year.

\section{Measurement Techniques}

The LH, FSH and TT levels were determined by automatic systems (Elecsys 2010 of Roche) based on the sandwich principle and electrochemiluminescence immunoassay. The blood sample was collected at 7:00 am-8:00 am. Normal values for males were $\mathrm{LH}=1.5-9.3 \mathrm{IU} / \mathrm{L}, \mathrm{FSH}$
$=1.4-18.1 \mathrm{IU} / \mathrm{L}$ and TT $=13.4-23.6 \mathrm{nmol} / \mathrm{L}$. The detection limit for LH was $0.2-250 \mathrm{IU} / \mathrm{L}$, that for FSH was $0.1-200$ $\mathrm{IU} / \mathrm{L}$ and that for TT was $0.1-222 \mathrm{nmol} / \mathrm{L}$.

All patients underwent semen analysis every 3 months according to the 2010 WHO standards ${ }^{10}$ to analyse the semen volume, sperm density and sperm morphology. Sperm motility was divided into three groups, namely, progressive motility (PR), non-progressive motility (NP) and immotility (IM). Semen was obtained by masturbation and then placed in a neutral plastic vial. Samples were examined by a microscope $(20 \times$ and $40 \times$ objective lens).

The volume of the testes was measured by the Prader orchidometer, and the average volume of bilateral TV was also analysed. The stretch penis length was measured from the pubic bone to the tip of the dorsal part of the stretched flaccid penis.

\section{Statistical Analysis}

The R 3.6.2 software was used for the statistical analysis of data. The measurement data, such as normal 
distribution, were described by the mean \pm standard deviation $(\mathrm{X} \pm \mathrm{SD})$. If the distribution was skewed in accordance with the median, then the median was used. The comparison of follow-up data differences from the two groups was examined by the paired $t$-test or MannWhitney's $U$-test depending on the distribution of variables. $\mathrm{P}<0.05$ suggested that the difference was statistically significant. All charts were built with R graphic.

\section{Results}

The average age of patients was 30 years old $(30.2 \pm 5.6)$. Among them were 10 married patients (52.6\%) and nine unmarried patients (47.4\%). No significant difference in age, height, basal TV and LH, FSH and TT levels in the partial and total $\mathrm{MHH}$ groups (Table 1). However, the difference in penis length was significant $(\mathrm{P}=0.005)$ (Figure 2). The causes of $\mathrm{MHH}$ in patients include hypopituitarism (47.4\%), Kallmann syndrome (26.3\%), pituitary adenoma (15.8\%), after basilar skull surgery $(5.26 \%)$ and unknown etiology (5.26\%). The average dose of hCG was $5000 \mathrm{IU}$ per dose $(5579 \pm 1773.7 \mathrm{IU})$, and the lowest dose was 3000 IU twice a week. The highest dose for hCG was 10,000 IU at 2-3 times per week. The detailed information followed one patient had 3,00 IU, 15 patients had $5000 \mathrm{IU}$, one patient had $8000 \mathrm{IU}$, and two patients had 10,000 IU.

Before treatment, mean TT level was $0.76 \pm 1.84$ (in the range $0.08-8.2) \mathrm{nmol} / \mathrm{mL}$. After 6 months with $\mathrm{CC}$ and hCG therapy, mean TT level sharply increased to $17.9 \pm 6.07$ (in the range range $12.1-34.1) \mathrm{nmol} / \mathrm{mL}$. The mean TT level was $19.6 \pm 5.6$ (in the range $12.2-33$ ) $\mathrm{nmol} / \mathrm{mL}$ after 12 months of treatment. This change was statistically different $(\mathrm{p}<0.001)$. The average testes volume, height and stretch penis length were also statistically increased after treatment. All details are described in Table 2. The change of clinical features in all patients and the total $\mathrm{MHH}$ group was statistically significant $(\mathrm{P}<0.001)$. In particular, the differences in testosterone hormone levels in the partial $\mathrm{MHH}$ group were also noted $(\mathrm{P}=0.03)$ (Figures 2 and 3).

No adverse event was noted in our study.

Nine patients had sperm in their semen (47.4\%).All partial $\mathrm{MHH}$ patients $(100 \%)$ and $37.5 \%$ of total $\mathrm{MHH}$ patients showed restoration of spermatogenesis. The earliest sperm appearance was 3 months after treatment (Table 3).

In the abovementioned nine cases, two had natural conception and childbirth, and two underwent IVF-ICSI; one case achieved children, whereas the other had frozen embryos but did not achieve pregnancy yet. Seven of the nine cases underwent sperm vitrification for fertility purposes in the future. The characteristics of sperm in nine patients was shown in Table 4.The sperm concentration under the combination treatment with hCG and $\mathrm{CC}$ was usually less than 5 million/mL. The highest sperm concentration was 24 million $/ \mathrm{mL}$, which was achieved in a patient with partial MHH. Evaluation of motility and morphology showed that the average progressive motility rate was below $8 \%$, and the normal morphological rate was $1 \%$ or lower.

\section{Discussion}

Recently, several studies have evaluated the effectiveness of $\mathrm{CC}$ in treating male infertility patients. The mechanism of action of CC involves the inhibition of the negative feedback of oestrogen at the level of the hypothalamus and pituitary, thereby increasing FSH and LH concentrations. LH stimulates Leydig cells to increase the secretion of testosterone. ${ }^{11,12}$ $\mathrm{CC}$ has been approved by the FDA to treat ovarian dysfunction and has been shown to have a beneficial effect on male hypogonadism. ${ }^{12}$ Most randomised controlled clinical trials showed that $\mathrm{CC}$ has a significant effect on the concentration of FSH and testosterone in plasma. ${ }^{13,14}$ In our study, we just only measured FSH before treatment. For that reason, testosterone was measured to evaluate the effect of combination.

Table I Baseline Clinical Data of the 2 Groups of Patients with $\mathrm{HH}$

\begin{tabular}{|l|l|l|l|l|}
\hline Clinical Features & Total HH $(\mathbf{n}=\mathbf{~ 1 6 )}$ & Partial HH $(\mathbf{n}=\mathbf{3})$ & All $(\mathbf{n}=\mathbf{1 9})$ & P-value \\
\hline Age (year) & $29.6 \pm 5.7$ & $33.3 \pm 5.1$ & $30.2 \pm 5.6$ & 0.33 \\
Height (cm) & $159.1 \pm 13.1$ & $168.0 \pm 5.3$ & $160.5 \pm 12.5$ & 0.08 \\
Penis length (cm) & $7.4 \pm 1.9$ & $11.2 \pm 1.1$ & $8.0 \pm 2.26$ & 0.005 \\
Basal TV (mL) & $2.8 \pm 1.5$ & $9.0 \pm 3.0$ & $3.8 \pm 2.9$ & 0.06 \\
LH (IU/L) & $0.6 \pm 0.5$ & $1.0 \pm 0.4$ & $0.7 \pm 0.5$ & 0.2 \\
FSH (IU/L) & $0.6 \pm 0.8$ & $1 \pm 0.8$ & $0.9 \pm 0.8$ & 0.8 \\
TT (nmol/L) & $0.9 \pm 2.0$ & $0.2 \pm 0.1$ & $0.8 \pm 1.8$ & 0.2 \\
\hline
\end{tabular}

Notes: Normal values for males were $\mathrm{LH}=1.5$ to $9.3 \mathrm{IU} / \mathrm{L}$, FSH $=1.4$ to $18.1 \mathrm{IU} / \mathrm{L}$, and $\mathrm{TT}=13.4$ to $23.6 \mathrm{nmol} / \mathrm{L}$. The detection limit for LH was 0.2 to $250 \mathrm{IU} / \mathrm{L}$, for FSH was 0.1 to $200 \mathrm{IU} / \mathrm{L}$, and for TT was 0.1 to $222 \mathrm{nmol} / \mathrm{L}$. 


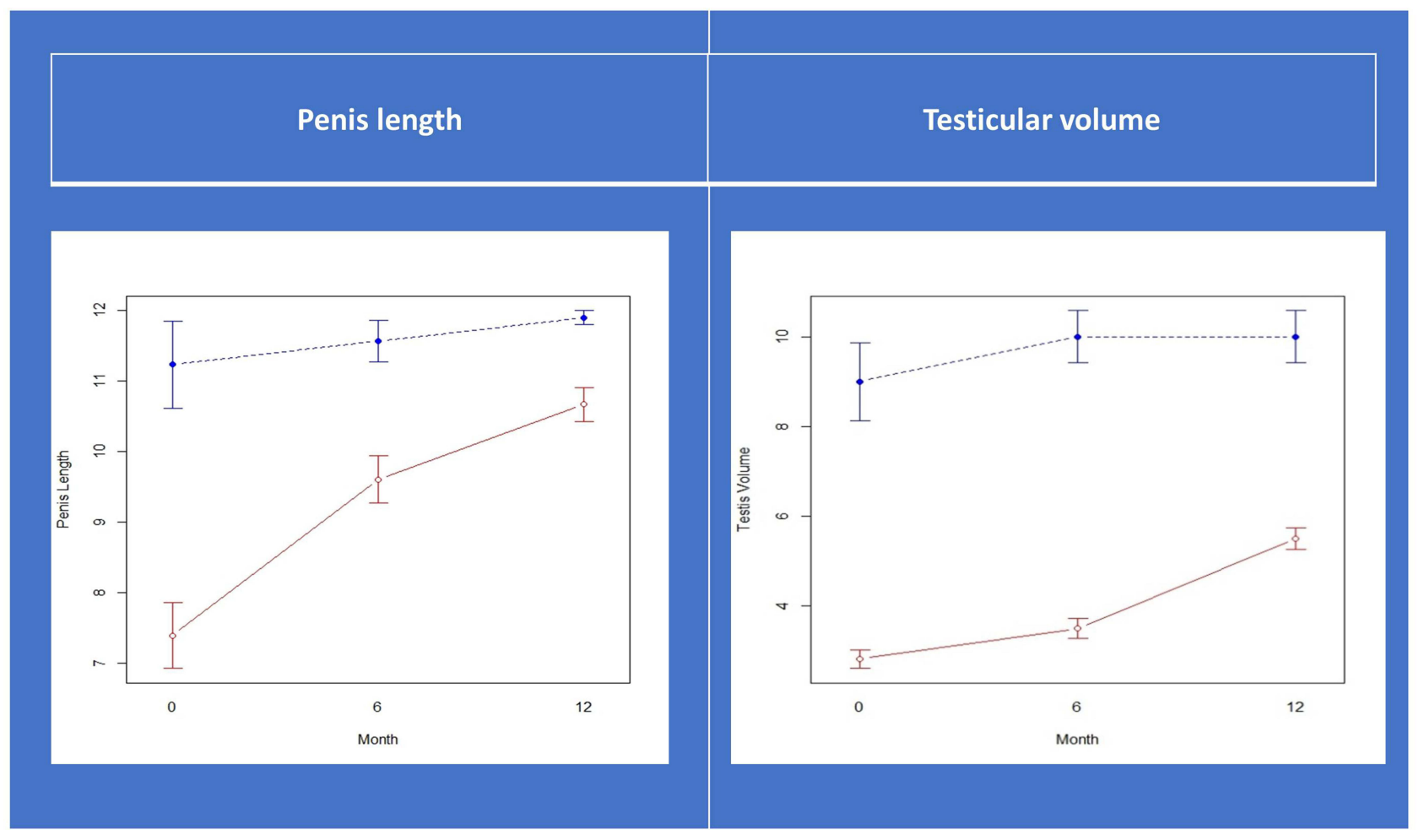

Figure 2 Penis length and testicular volume. (blueline: partial $\mathrm{HH}$, redline: total $\mathrm{HH}$ ).

However, the improvement of semen parameters is controversial. A number of randomised controlled clinical trials suggested that $\mathrm{CC}$ does not change the semen parameters. ${ }^{15}$ Some reports have suggested that CC improves sperm count and pregnancy rate. ${ }^{14,16,17}$ In our study, the subjects were patients with MHH whose spermatogenesis had not occurred, and thus, increasing hormone levels was an important goal for these patients.
In the present study, we aimed to assess the efficacy of combined therapy $(\mathrm{CC}+\mathrm{hCG})$ in spermatogenesis. We conducted this study to find out if adding $\mathrm{CC}$ to hCG treatment would be beneficial. Objectively, we found that such a combination of hCG + CC was effective in restoring normal hormone secretion, especially testosterone serum levels, after 12 months. The effect of stimulating sperm production with $\mathrm{hCG}+\mathrm{CC}$ in our study after 12

Table 2 Features Changes Before and After Treatment

\begin{tabular}{|c|c|c|c|c|c|}
\hline Features & Group & $\begin{array}{l}\text { First Visit X } \pm \text { SD; Min- } \\
\text { Max }\end{array}$ & $\begin{array}{l}6 \text { Months After Treatment } \\
\text { X } \pm \text { SD; Min-Max }\end{array}$ & $\begin{array}{l}\text { I } 2 \text { Months After Treatment } \\
\text { X } \pm \text { SD; Min-Max }\end{array}$ & p-value \\
\hline Height & $\begin{array}{l}\text { Total HH } \\
\text { Partial HH } \\
\text { All }\end{array}$ & $\begin{array}{l}159.1 \pm 13.1(137-184) \\
168 \pm 5.3(162-172) \\
160.5 \pm 12.5(137-184)\end{array}$ & $\begin{array}{l}160.2 \pm 12.9(137-184) \\
168.7 \pm 4.2(164-172) \\
161.5 \pm 12.3(137-184)\end{array}$ & $\begin{array}{l}162.1 \pm 11.9(142-184) \\
168.7 \pm 4.2(164-172) \\
163.1 \pm 11.3(142-184)\end{array}$ & $\begin{array}{l}<0.001 \\
0.4226 \\
<0.001\end{array}$ \\
\hline Penis Length & $\begin{array}{l}\text { Total HH } \\
\text { Partial HH } \\
\text { All }\end{array}$ & $\begin{array}{l}7.4 \pm 1.9(5-12.7) \\
11.2 \pm 1.1(10-12) \\
8 \pm 2.3(5-12.7)\end{array}$ & $\begin{array}{l}9.6 \pm 1.4(7-12.7) \\
11.57 \pm 0.5(11-12) \\
9.91 \pm 1.4(7-12.7)\end{array}$ & $\begin{array}{l}10.7 \pm 0.9(9-12.7) \\
11.9 \pm 0.2(11.7-12) \\
10.86 \pm 0.9(9-12.7)\end{array}$ & $\begin{array}{l}<0.001 \\
0.4226 \\
<0.001\end{array}$ \\
\hline $\begin{array}{l}\text { Testicular } \\
\text { Volume }\end{array}$ & $\begin{array}{l}\text { Total HH } \\
\text { Partial HH } \\
\text { All }\end{array}$ & $\begin{array}{l}2.8 \pm 1.5(1-6) \\
9 \pm 3(6-12) \\
3.8 \pm 2.9(1-12)\end{array}$ & $\begin{array}{l}3.5 \pm 1.6(1-6) \\
10 \pm 2(8-12) \\
4.5 \pm 2.9(I-12)\end{array}$ & $\begin{array}{l}5.5 \pm 1.8(2-8) \\
10 \pm 2(8-12) \\
6.2 \pm 2.4(2-12)\end{array}$ & $\begin{array}{l}<0.001 \\
0.2254 \\
<0.001\end{array}$ \\
\hline $\begin{array}{l}\text { Testosterone } \\
\text { Level }\end{array}$ & $\begin{array}{l}\text { Total HH } \\
\text { Partial HH } \\
\text { All }\end{array}$ & $\begin{array}{l}0.9 \pm 2(0.08-8.2) \\
0.2 \pm 0.1(0.08-0.3) \\
0.76 \pm 1.84(0.08-8.2)\end{array}$ & $\begin{array}{l}17.9 \pm 6.0 \mid(|2 .|-34.1) \\
I 7.9 \pm 6.1(\mid 3.5-22.2) \\
I 7.9 \pm 6.07(|2 .|-34.1)\end{array}$ & $\begin{array}{l}19.4 \pm 5.6(12.2-33) \\
20.7 \pm 6.3(15.6-27.8) \\
19.6 \pm 5.6(12.2-33)\end{array}$ & $\begin{array}{l}<0.001 \\
0.03 \\
<0.001\end{array}$ \\
\hline
\end{tabular}




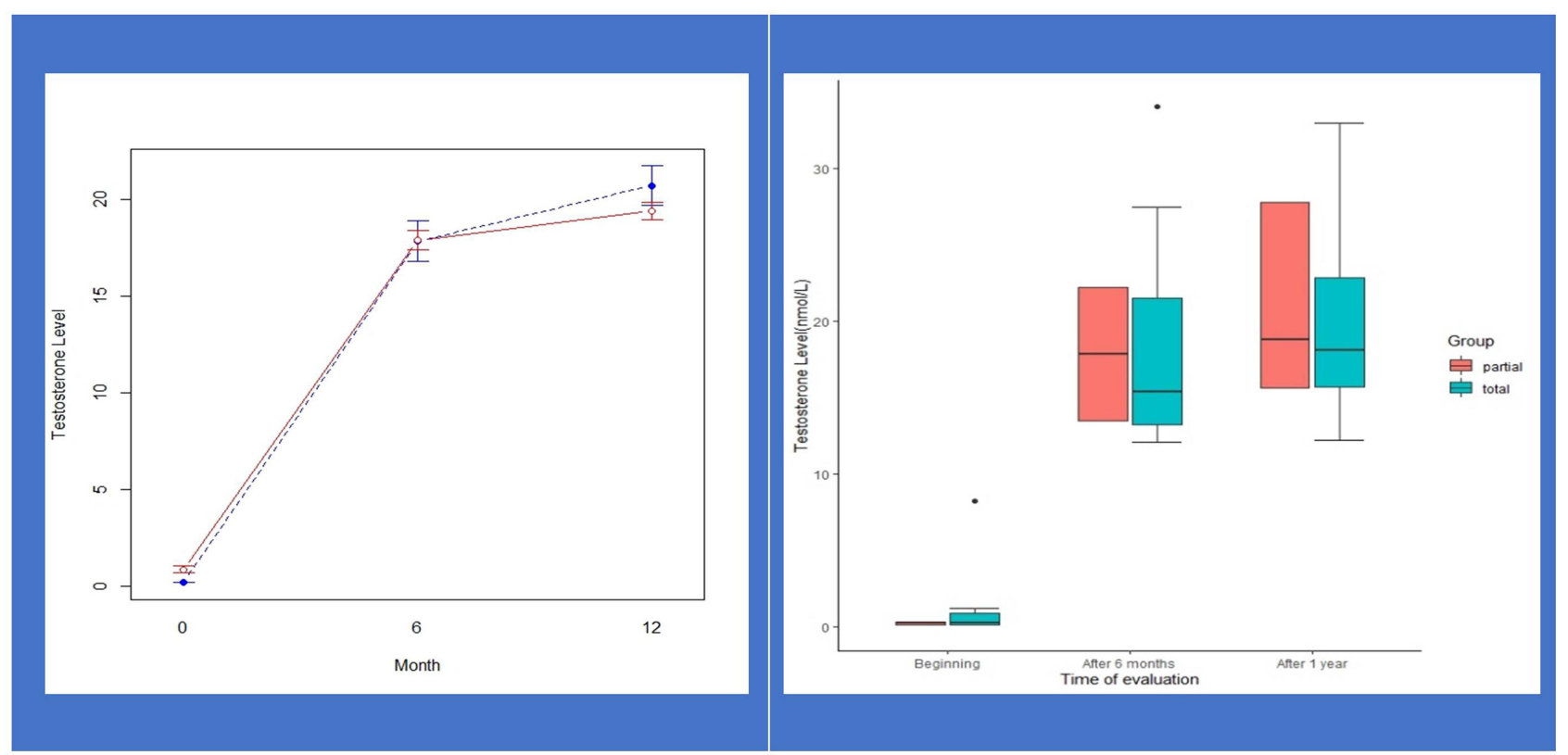

Figure 3 Testosterone level. (blueline: partial $\mathrm{HH}$, redline: total $\mathrm{HH}$ ).

months was 9 (47.4\%). This was considerably low, because the follow-up time in our study was not long enough. Indeed, in Vietnam, detection is often late for men who are infertile due to secondary hypogonadism, and the treatment is often long and difficult, resulting in high costs and failed results. Couples desire to have children as soon as possible. In some cases in our study, when no sperm was found in the semen after 12 months, the couple refused the subsequent treatment, instead switching to an alternative regimen and accepting donor sperm for the next steps. With early sperm production time and 6 months follow-up period, Lin et al reported that GnRH infused subcutaneously was a preferred method than the combination of hCG and human menopausal gonadotropin. ${ }^{18}$ In our study, we did not have a control group, but we used $\mathrm{CC}$, which has been proven as effective in improving the sperm count, sperm motility and the morphology of the sperms (to a certain extent). ${ }^{19}$ It effectively led to spermatogenesis.

In our study, spermatogenesis differed between the two subgroups of $\mathrm{MHH}$. The rate of sperm appearance in the semen of the total $\mathrm{MHH}$ group was 7/16 (43.75\%), whereas this was $100 \%$ in the partial $\mathrm{MHH}$ group. These results were in line with those obtained by a study showing that hCG can complete the spermatogenesis in men with partial gonadotropin deficiency. ${ }^{20}$ No difference in hormonal profile was found between the two groups but the differences in height, penis length and testicular volume were statistically significant, showing that we can use clinical evaluation to predict the success rate as in some previous studies, in which the response to hCG of patients with MHH was predicted (especially in terms of the testicular volume). ${ }^{20,21}$ In our study, the testicular volume of most unsuccessful cases ranged from $1 \mathrm{~mL}$ to $2 \mathrm{~mL}$. Larger testicular volume was a useful prognostic indicator of response and was a predictor of fertility outcome. ${ }^{22}$ The quality of sperm recovered in our study was low with 7/9 (77.7\%) showing deformed morphology. There were two cases with normal morphology, but they differed in etiology, concentration and motility.

In our study, one special patient was classified into the total $\mathrm{MHH}$ group even if he had puberty symptoms (Tanner 3) at initial evaluation, ie, Tanner 2 according to the testicular volume $(5 \mathrm{~mL})$ and Tanner 4 according to the

Table 3 The Appearance of Sperm in Semen

\begin{tabular}{|l|l|l|l|l|}
\hline $\begin{array}{l}\text { Sperm } \\
\text { Appearance } \\
\text { Group }\end{array}$ & $\begin{array}{l}\text { After 3 } \\
\text { Months } \\
\text { N (\%) }\end{array}$ & $\begin{array}{l}\text { After 6 } \\
\text { Months } \\
\text { N (\%) }\end{array}$ & $\begin{array}{l}\text { After 9 } \\
\text { Months } \\
\text { N (\%) }\end{array}$ & $\begin{array}{l}\text { After I2 } \\
\text { Months } \\
\text { N (\%) }\end{array}$ \\
\hline $\begin{array}{l}\text { Total HH } \\
(n=16)\end{array}$ & $0(0 \%)$ & $2(12.5 \%)$ & $4(25 \%)$ & $6(37.5 \%)$ \\
\hline $\begin{array}{l}\text { Partial HH } \\
(n=3)\end{array}$ & $2(66.7 \%)$ & $3(100 \%)$ & $3(100 \%)$ & $3(100 \%)$ \\
\hline All $(n=19)$ & $2(10.5 \%)$ & $5(I 1.1 \%)$ & $7(I 1.1 \%)$ & $9(47.4 \%)$ \\
\hline
\end{tabular}


Table 4 Characteristics of Sperm

\begin{tabular}{|c|c|c|c|c|}
\hline Code & Etiology & Concentration $\left(10^{\wedge} / \mathrm{mL}\right)$ & PR (\%) & Sperm Morphology (\%) \\
\hline $\mathrm{HH} 03$ & Hypopituitarism & 3 & 4 & $<1$ \\
\hline $\mathrm{HH} 08$ & Hypopituitarism & 3 & 8 & $<1$ \\
\hline $\mathrm{HH} 09$ & Hypopituitarism & 4 & 10 & $<1$ \\
\hline $\mathrm{HHIO}$ & Pituitary adenoma & 0.1 & 5 & 1 \\
\hline $\mathrm{HHII}$ & Kallmann syndrome & 24 & 16 & I \\
\hline $\mathrm{HHI} 3$ & Hypopituitarism & 4 & 8 & $<1$ \\
\hline $\mathrm{HHI} 4$ & Kallmann syndrome & I & 13 & $<1$ \\
\hline $\mathrm{HHI} 6$ & Pituitary adenoma (after 4 times surgery) & 2 & 5 & $<1$ \\
\hline HHI8 & Hypopituitarism & 4 & 5 & $<1$ \\
\hline Mean & 5 & 8 & $<1$ & \\
\hline
\end{tabular}

Abbreviations: $\mathrm{HH}$, hypogonadotropic hypogonadism, PR-progressive motility.

hair distribution, because he had been using testosterone therapy for 12 consecutive years. Sperm appeared in his semen after 13 months of follow-up.

In accordance with spermatogenesis, secondary sex characteristics also developed. After treatment, a steadily increasing trend with statistically significance in height, penis length and testicular volume was observed in the total MHH group in particular. However, such a trend was not shown in the partial MHH group. We also noted that the oldest person (37 years old) was still growing (up to $5 \mathrm{~cm}$ ). Moreover, the tallest height reached (up to $8 \mathrm{~cm}$ ) was observed in a 24-year-old patient. Testicular volume was increased by about two times after 12 months. Our therapy increased serum testosterone level, which in turn induced and maintained secondary sex characteristics and also improved the quality of life and well-being, especially in patients aiming to become fertile. ${ }^{23}$

Testosterone level increased by approximately 25 times (mean) and was at a normal range at 12 months after treatment. Mean TT level was $0.76 \pm 1.84 \mathrm{nmol} / \mathrm{mL}$ (at baseline), which increased to $17.9 \pm 6.07 \mathrm{nmol} / \mathrm{mL}$ at 6 months after treatment and to $19.6 \pm 5.6 \mathrm{nmol} / \mathrm{mL}$ after 12 months of treatment. Testosterone level increased quickly and was maintained after 12 months of treatment with the combination of hCG and CC. Such combination therapy was effective for normalising testosterone level. When the testosterone level became normal, the development of sex characteristics was enhanced. Gonadotropin normalised testosterone level; spermatogenesis began even without the use of exogenous testosterone.
The most important issue when using hCG to treat $\mathrm{MHH}$ and to achieve the desired outcomes was the dose and duration of treatment. ${ }^{24}$ In the present study, the group was treated with $\mathrm{CC}$ at $25 \mathrm{mg}$ daily and hCG at an average dose of $5000 \mathrm{IU}$ administered twice weekly (i.m. or s.c.). To support endogenous testosterone production for the period of infertility treatment, hCG treatment can be administered at the appropriate dosage to prevent serum FSH level suppression. ${ }^{25}$ In this situation, through a negative feedback mechanism, CC supported the effect of hCG and optimised the treatment.

The hormone hCG induces testosterone production by stimulating Leydig cells directly. Its effect is similar to that of LH, but its elimination half-life is longer than that of LH, thereby avoiding the need for daily injections. The level of testicular testosterone increased, thereby inducing the onset of spermatogenesis ${ }^{21,26}$ and stimulating Sertoli cell maturation and proliferation. ${ }^{21,27}$ Kobori et al reported that by using hCG, spermatogenesis was restored in five of the seven patients with adult-onset idiopathic hypogonadotropic hypogonadism. ${ }^{28} \mathrm{FSH}$ was not considered for $\mathrm{MHH}$ treatment because the role of FSH in stimulating spermatogenesis is not fully adequate and need further studies. $^{21,29}$ Thus, using FSH alone as initial therapy did not show a good outcome. ${ }^{29}$ In addition, FSH treatment is expensive and is not appropriate for developing countries like Vietnam.

$\mathrm{CC}$ is an orally active nonsteroidal agent distantly related to diethylstilboestrol. ${ }^{30} \mathrm{CC}$ induces the Leydig cells in the testes to produce testosterone, which together 
with FSH induces spermatogenesis. ${ }^{19}$ Moreover, masculinisation of the brain during development and maintenance of sexual behaviour in adult males were also noted in rats $^{31}$ when CC was administered. Published data suggested that CC may be an appropriate alternative treatment for male hypogonadism, because it is safe, cheap and effective for improving serum testosterone levels in men who wish to preserve their fertility. ${ }^{8,9}$ Da Ros et al concluded that $\mathrm{CC}$ should be considered as a therapy for men with symptomatic hypogonadism. ${ }^{32}$ However, few studies have investigated the use of $\mathrm{CC}$ in $\mathrm{MHH}$ treatment. Available data suggested that clomiphene is an efficient and convenient alternative to testosterone replacement therapy in a substantial subset of patients with late-onset hypogonadotropic hypogonadism (at 6-8 weeks following initiation of treatment). ${ }^{33}$ Our study supported these results with the use of $25 \mathrm{mg} \mathrm{CC}$ combined with hCG in the treatment of MHH. As the same effect of hCG, a daily dose of $25 \mathrm{mg} \mathrm{CC}$ could given the contribution that resulted in increased post-treatment testosterone levels and improvement of the quality of life. Moreover, using $\mathrm{CC}$ also has economic benefits. Taylor and Levine found that $\mathrm{CC}$ was a less expensive option with minor side effects for men with hypogonadism. ${ }^{30}$ In addition, it had no effect on the change of prostate-specific antigen or haematocrit values ${ }^{34}$ thereby helping us evaluate the side effect of $\mathrm{hCG}^{23}$ with minimal bias.

Studies have investigated the side effects of CC medication. Side effects of the drug include headache, dizziness, gynecomastia and exacerbation of mental illness. However, according to this study, CC is generally considered to be safe and well-tolerated. ${ }^{11}$ Side effects of hCG are reportedly mild even with prolonged use and high doses. Some side effects include the following: headache; feeling restless or irritable; mild swelling or water weight gain; depression; feeling tired; breast tenderness or swelling; pain; hypertension; polycythaemia; increased haematocrit; and acne. To avoid these side effects, we used a combination of hCG and $\mathrm{CC}$ to reduce the dose of hCG and increase the effectiveness of the treatment. In our study, 19 patients with MHH did not report any drug side effects.

hCG and/or CC treatments protect the testis. ${ }^{35}$ The effectiveness of hCG alone or in combination with $\mathrm{CC}$ has been reported. ${ }^{36}$ The combination of hCG $+\mathrm{CC}$ is a safe, low-cost and effective treatment that can be used to preserve fertility capacity. We have not been able to demonstrate that the dose of hCG is reduced in the combination of $\mathrm{CC}$ and hCG due to the small and rare number of samples. Further studies are required to evaluate a larger population. Society should focus on patients with hypogonadism who need access to healthcare earlier, because monitoring the impact of the condition on longterm health and psychosocial function is necessary.

\section{Limitation}

The main limitation of the present study was that we did not have a control group. This was considered impossible, because all the enrolled participants wished to maintain their fertility.

\section{Conclusion}

In conclusion, a combination of hCG and $\mathrm{CC}$ may be an option for MHH patients who desired to restore their fertility. After 12 months, $52.63 \%$ of patients showed the restoration of spermatogenesis, and spermatozoa appeared in semen. Testosterone level increased by approximately 25 times by mean and was in the normal range at 12 months after treatment. Secondary sexual characteristics improved significantly, especially the increase in body height and penile length, even in the patients over 18 years old. This therapy was considered safe because no adverse event was noted.

\section{Abbreviations}

$\mathrm{MHH}$, male hypogonadotropic hypogonadism; total $\mathrm{HH}$, total hypogonadotropic hypogonadism; partial $\mathrm{HH}$, partial hypogonadotropic hypogonadism; CC, clomiphene citrate; hCG, human chorionic gonadotropin.

\section{Data Sharing Statement}

The datasets used and/or analyzed during the current study available from the corresponding author on reasonable request.

\section{Ethics Approval and Consent to Participate}

The Ethics Committee of Vietnam Military Medical University approved the study protocol (QD/HVQY) and authorized its conduct and follow-up. The study was in line with the Declaration of Helsinki. Individual patient consent for inclusion in the study was obtained. Before treatment, written informed consent was provided to all participants after a thorough explanation of the purpose of this study. 
Patients had signed in written informed consent. Patients had the right to discontinue at any time during the study.

\section{Author Contributions}

All authors made a significant contribution to the work reported, whether that is in the conception, study design, execution, acquisition of data, analysis and interpretation, or in all these areas; took part in drafting, revising or critically reviewing the article; gave final approval of the version to be published; have agreed on the journal to which the article has been submitted; and agree to be accountable for all aspects of the work.

\section{Funding}

There is no funding to report.

\section{Disclosure}

The authors declare that they have no conflicts of interest for this work.

\section{References}

1. Fraietta R, Zylberstejn DS, Esteves SC. Hypogonadotropic hypogonadism revisited. Clinics (Sao Paulo). 2013;68 Suppl 1 (Supp11):81-88.

2. Sato N, Hasegawa T, Hasegawa Y, et al. Treatment situation of male hypogonadotropic hypogonadism in pediatrics and proposal of testosterone and gonadotropins replacement therapy protocols. Clin Pediatr Endocrinol. 2015;24(2):37-49. doi:10.1297/cpe.24.37

3. Jungwirth A, Giwercman A, Tournaye H, et al. European Association of Urology guidelines on Male Infertility: the 2012 update. Eur Urol. 2012;62(2):324-332. doi:10.1016/j.eururo.2012.04.048

4. Mulhall JP, Trost LW, Brannigan RE, et al. Evaluation and management of testosterone deficiency: AUA guideline. $J$ Urol. 2018;200 (2):423-432. doi:10.1016/j.juro.2018.03.115

5. Han TS, Bouloux PMG. What is the optimal therapy for young males with hypogonadotropic hypogonadism? Clin Endocrinol (Oxf). 2010;72(6):731-737. doi:10.1111/j.1365-2265.2009.03746.x

6. Jung JH, Seo JT. Empirical medical therapy in idiopathic male infertility: promise or panacea? Clin Exp Reprod Med. 2014;41 (3):108-114. doi:10.5653/cerm.2014.41.3.108

7. Fink J, Schoenfeld BJ, Hackney AC, Maekawa T, Horie S. Human chorionic gonadotropin treatment: a viable option for management of secondary hypogonadism and male infertility. Expert Rev Endocrinol Metab. 2021;16(1):1-8. doi:10.1080/17446651.2021.1863783

8. Katz DJ, Nabulsi O, Tal R, Mulhall JP. Outcomes of clomiphene citrate treatment in young hypogonadal men. BJU Int. 2012;110 (4):573-578. doi:10.1111/j.1464-410X.2011.10702.x

9. Moskovic DJ, Katz DJ, Akhavan A, Park K, Mulhall JP. Clomiphene citrate is safe and effective for long-term management of hypogonadism. BJU Int. 2012;110(10):1524-1528. doi:10.1111/ j.1464-410X.2012.10968.x

10. Rothmann SA, Bort A-M, Quigley J, Pillow R. Sperm morphology classification: a rational method for schemes adopted by the World Health Organization. In: Carrell DT, Aston KI, editors. Spermatogenesis. Springer; 2013:27-37.
11. Wheeler KM, Sharma D, Kavoussi PK, Smith RP, Costabile R. Clomiphene Citrate for the Treatment of Hypogonadism. Sex Med Rev. 2019;7(2):272-276. doi:10.1016/j.sxmr.2018.10.001

12. Earl JA, Kim ED. Enclomiphene citrate: a treatment that maintains fertility in men with secondary hypogonadism. Expert Rev Endocrinol Metab. 2019;14(3):157-165. doi:10.1080/ 17446651.2019.1612239

13. Helo S, Ellen J, Mechlin C, et al. A Randomized Prospective Double-Blind Comparison Trial of clomiphene citrate and anastrozole in raising testosterone in hypogonadal infertile men. $J$ Sex Med. 2015;12(8):1761-1769. doi:10.1111/jsm. 12944

14. Surbone A, Vaucher L, Primi MP, et al. Clomiphene citrate effect on testosterone level and semen parameters in 18 infertile men with low testosterone level and normal/low gonadotropines level. Eur J Obstet Gynecol Reprod Biol. 2019;238:104-109. doi:10.1016/j. ejogrb.2019.05.011

15. World Health Organization. A double-blind trial of clomiphene citrate for the treatment of idiopathic male infertility. Int $J$ Androl. 1992;15(4):299-307. doi:10.1111/j.1365-2605.1992.tb01129.x

16. Sharma D, Zillioux J, Khourdaji I, et al. Improvements in semen parameters in men treated with clomiphene citrate-A retrospective analysis. Andrologia. 2019;51(5):e13257. doi:10.1111/and.13257

17. Chua ME, Escusa KG, Luna S, Tapia LC, Dofitas B, Morales M. Revisiting oestrogen antagonists (clomiphene or tamoxifen) as medical empiric therapy for idiopathic male infertility: a meta-analysis. Andrology. 2013;1(5):749-757. doi:10.1111/j.2047-2927.2013.00107.x

18. Lin J, Mao J, Wang X, Ma W, Hao M, Wu X. Optimal treatment for spermatogenesis in male patients with hypogonadotropic hypogonadism. Medicine (Baltimore). 2019;98(31):e16616. doi:10.1097/MD.0000000000016616

19. Patankar SS, Kaore SB, Sawane MV, Mishra NV, Deshkar AM. Effect of clomiphene citrate on sperm density in male partners of infertile couples. Indian J Physiol Pharmacol. 2007;51(2):195-198.

20. Burris AS, Rodbard HW, Winters SJ, Sherins RJ. Gonadotropin therapy in men with isolated hypogonadotropic hypogonadism: the response to human chorionic gonadotropin is predicted by initial testicular size. J Clin Endocrinol Metab. 1988;66(6):1144-1151. doi:10.1210/jcem-66-6-1144

21. Rey RA, Grinspon RP, Gottlieb S, et al. Male hypogonadism: an extended classification based on a developmental, endocrine physiology-based approach. Andrology. 2013;1(1):3-16. doi:10.1111/j.2047-2927.2012.00008.x

22. Liu PY, Baker HWG, Jayadev V, Zacharin M, Conway AJ, Handelsman DJ. Induction of spermatogenesis and fertility during gonadotropin treatment of gonadotropin-deficient infertile men: predictors of fertility outcome. J Clin Endocrinol Metab. 2009;94 (3):801-808. doi:10.1210/jc.2008-1648

23. Bhasin S, Brito JP, Cunningham GR, et al. Testosterone therapy in men with hypogonadism: an Endocrine Society Clinical Practice Guideline. J Clin Endocrinol Metab. 2018;103(5):1715-1744. doi:10.1210/jc.2018-00229

24. Yılmazel FK, Karabulut İ, Yılmaz AH, Keskin E, Bedir F, Özbey İ. A review of hypogonadotropic hypogonadism cases followed up in our clinic in the last decade. Urologia. 2019;391560319882231. doi:10.1177/0391560319882231

25. Dwyer AA, Raivio T, Pitteloud N. Gonadotrophin replacement for induction of fertility in hypogonadal men. Best Pract Res Clin Endocrinol Metab. 2015;29(1):91-103. doi:10.1016/j.beem.2014.10.005

26. Rey RA, Musse M, Venara M, Chemes HE. Ontogeny of the androgen receptor expression in the fetal and postnatal testis: its relevance on Sertoli cell maturation and the onset of adult spermatogenesis. Microsc Res Tech. 2009;72(11):787-795. doi:10.1002/jemt.20754

27. Pasqualini T, Chemes H, Rivarla MA. Testicular testosterone levels during puberty in cryptorchidism. Clin Endocrinol (Oxf). 1981;15 (6):545-554. doi:10.1111/j.1365-2265.1981.tb00700.x 
28. Kobori Y, Suzuki K, Iwahata T, et al. Hormonal therapy (hCG and $\mathrm{rhFSH}$ ) for infertile men with adult-onset idiopathic hypogonadotropic hypogonadism. Syst Biol Reprod Med. 2015;61(2):110-112. doi:10.3109/19396368.2014.994789

29. Huhtaniemi IT. The role of mutations affecting gonadotrophin secretion and action in disorders of pubertal development. Best Pract Res Clin Endocrinol Metab. 2002;16(1):123-138. doi:10.1053/beem.2002.0185

30. Taylor F, Levine L. Clomiphene citrate and testosterone gel replacement therapy for male hypogonadism: efficacy and treatment cost. J Sex Med. 2010;7(1 Pt 1):269-276. doi:10.1111/j.1743-6109.2009.01454.x

31. Lauber ME, Sarasin A, Lichtensteiger W. Sex differences and androgen-dependent regulation of aromatase (CYP19) mRNA expression in the developing and adult rat brain. J Steroid Biochem Mol Biol. 1997;61(3-6):359-364. doi:10.1016/S0960-0760(97)80033-7

32. Da Ros CT, Averbeck MA. Twenty-five milligrams of clomiphene citrate presents positive effect on treatment of male testosterone deficiency - a prospective study. Int Braz J Urol. 2012;38 (4):512-518. doi:10.1590/S1677-55382012000400011
33. Liel Y. Clomiphene citrate in the treatment of idiopathic or functional hypogonadotropic hypogonadism in men: a case series and review of the literature. Endocr Pract. 2017;23(3):279-287. doi:10.4158/ EP161543.OR

34. Chandrapal JC, Nielson S, Patel DP, et al. Characterising the safety of clomiphene citrate in male patients through prostate-specific antigen, haematocrit, and testosterone levels. BJU Int. 2016;118(6):994-1000. doi:10.1111/bju. 13546

35. Crosnoe-Shipley LE, Elkelany OO, Rahnema CD, Kim ED. Treatment of hypogonadotropic male hypogonadism: case-based scenarios. World J Nephrol. 2015;4(2):245-253. doi:10.5527/wjn. v4.i2.245

36. Habous M, Giona S, Tealab A, et al. Clomiphene citrate and human chorionic gonadotropin are both effective in restoring testosterone in hypogonadism: a short-course randomized study. BJU Int. 2018;122 (5):889-897. doi:10.1111/bju.14401

\section{Publish your work in this journal}

Research and Reports in Urology is an international, peer-reviewed, open access journal publishing original research, reports, editorials, reviews and commentaries on all aspects of adult and pediatric urology in the clinic and laboratory including the following topics: Pathology, pathophysiology of urological disease; Investigation and treatment of urological disease; Pharmacology of drugs used for the treatment of urological disease. The manuscript management system is completely online and includes a very quick and fair peer-review system, which is all easy to use. Visit http://www.dovepress.com/ testimonials.php to read real quotes from published authors. 